\title{
Modification of Alternative Messenger RNA Splicing of Fibroblast Growth Factor Receptors in Human Cardiac Allografts during Rejection
}

\author{
Xiao-Ming Zhao, * William H. Frist, *‡ Tiong-Keat Yeoh, ${ }^{*}$ and Geraldine G. Miller*\$ \\ * Vanderbilt Transplant Center, Departments of ${ }^{\ddagger}$ Thoracic Surgery and ${ }^{\S}$ Medicine, Vanderbilt University School of Medicine, Nashville, \\ Tennessee 37232
}

\begin{abstract}
Accelerated coronary atherosclerosis in cardiac transplants (cardiac allograft vasculopathy, CAV) is characterized by coronary intimal hyperplasia. Acidic fibroblast growth factor (aFGF) is a potent mitogen for vascular smooth muscle cells and endothelial cells, and its expression is increased in cardiac allografts, suggesting it may play a role in the pathogenesis of CAV. The activity of aFGF is dependent on binding to transmembrane receptors. To investigate whether receptors for aFGF are also induced after transplantation, polymerase chain reaction, in situ hybridization, and immunohistochemistry were used to analyze expression of four receptors for aFGF (FGFR1-FGFR4). Expression of mRNA encoding extracellular immunoglobulin-like domains of FGFR1 was increased 35-fold in cardiac allografts compared with normal hearts and was predominantly present in cardiac myocytes and vascular structures. Alternatively spliced mRNA that encodes transmembrane forms of FGFR1, which contain the signal-transducing tyrosine kinase domains, was induced in allografts during rejection, in infiltrating cells, vascular structures, and myocytes. In vitro experiments showed that differential expression of FGF receptor isoforms was induced by aFGF, and also by IL-6 and TGF- $\beta$, which are expressed in cardiac allografts during rejection. The results show that expression of both aFGF and its receptors is altered in cardiac allografts and suggest that these events are important in the pathogenesis of CAV. (J. Clin. Invest. 1994. 94:992-1003.) Key words: allograft vasculopathy $\bullet$ heart transplantation $\bullet$ atherosclerosis $\bullet$ interleukin-6 - transforming growth factor- $\beta$
\end{abstract}

\section{Introduction}

A form of accelerated atherosclerosis, termed cardiac allograft vasculopathy (CAV), ${ }^{1}$ is the leading cause of late death in

Address correspondence to Geraldine Miller, M.D., A3310 Medical Center North, Vanderbilt University Medical School, Nashville, TN 37232.

Received for publication 15 September 1993 and in revised form 4 May 1994.

1. Abbreviations used in this paper: aFGF, acidic fibroblast growth factor; CAV, cardiac allograft vasculopathy; EC, endothelial cells; FGFR1-FGFR4, four receptors for aFGF; GAPDH, glyceraldehyde-3phosphate dehydrogenase; HUVEC, human umbilical vein endothelial cells; KEC, kidney endothelial cells; RT/PCR, reverse transcriptase PCR; SMC, smooth muscle cells.

J. Clin. Invest.

(C) The American Society for Clinical Investigation, Inc.

0021-9738/94/09/0992/12 \$2.00

Volume 94, September 1994, 992-1003 heart transplant recipients and is estimated to affect $>40 \%$ of recipients who survive over 4 yr after transplantation (1-3). Improvements in immunosuppressive treatment have had little impact on CAV (1, 2, 4-9), thus, this lesion is a major impediment to the long-term success of heart transplantation.

CAV differs from native atherosclerosis in its diffuse, concentric involvement of both small and large vessels and the rapidity with which it develops after transplantation $(1,3,10)$. The mechanisms underlying CAV are not well understood. Immunologic injury is suspected to play an important role in the development of CAV (11); although controversial, increasing clinical evidence supports a correlation between allograft rejection episodes and occurrence of CAV (1, 2, 4-9). Conventional risk factors for native atherosclerosis have not been well correlated with CAV (1, 2, 4-9, 12).

The histologic appearance of CAV typically demonstrates marked proliferation and hyperplasia of vascular smooth muscle cells (SMC) and endothelial cells (EC) with minimal intimal disruption $(3,10)$. These findings suggest that growth factors for SMC and EC may contribute to the pathogenesis of the disease. Fibroblast growth factors (FGF) and PDGF are believed to be important cofactors in the genesis of native atherosclerosis in which myointimal proliferation also occurs, but in a much more circumscribed fashion (13-16). Experiments reported recently have shown directly that in vivo introduction of a gene construct encoding acidic FGF (aFGF) into intimal cells of normal porcine iliofemoral arteries resulted in rapid and striking vascular SMC proliferation and vascular stenosis (17). Earlier studies, using a canine ischemia model, found that aFGF induced vascular SMC proliferation, similar to that seen in CAV, only in areas of ischemic injury (18). Data from other laboratories have demonstrated expression of basic FGF in human cardiac allografts (19). These results thus provide strong support for the hypothesis that growth factors, including aFGF, are important in the smooth muscle hyperplasia that is an integral part of atherosclerosis in transplanted hearts.

Our recent studies in transplanted human hearts have shown that expression of aFGF is increased significantly in the majority of cardiac allografts shortly after transplantation $(20,21)$. Human $\mathrm{T}$ cells, which are invariably present within allograft myocardium, also may be a source of aFGF (20). Thus, in human cardiac allografts, increased production of aFGF may be directly mitogenic for vascular SMC, and immunologic injury rather than ischemia may play a role in augmenting response to aFGF. Responsiveness to aFGF is dependent upon binding of this ligand to high affinity FGF receptors (FGFR). Changes in response to aFGF, therefore, could be mediated by alterations in expression of its receptors.

At least two of the four cloned receptors for aFGF, FGFR1 and FGFR2, exist in multiple isoforms due to alternative mRNA splicing $(22-27)$. This process, which occurs in a tissue-specific fashion in many eukaryotic cells, generates multiple 
mRNA transcripts from a single pre-mRNA. In this manner, diversity in protein structure and function is generated by expression of multiple isoforms from a single gene. In the case of FGFR1 and FGFR2 genes, alternative splicing results in receptors with different ligand affinities and distinct signaling capacities $(22,23,25-27)$. For example, isoforms of FGFR1 that are present in some normal tissues, including the heart (28, 29), lack the intracellular tyrosine kinase domain and hence are incapable of transducing mitogenic signals. The function of such receptors is not yet known.

In the present studies, we have used the reverse transcriptase/polymerase chain reaction (RT/PCR), in situ hybridization, and immunohistochemistry to examine expression of aFGF and FGF receptors in biopsies obtained from cardiac allografts and normal donor hearts before transplantation. The results demonstrate that expression of aFGF and one of the four FGF receptors, FGFR1, is increased significantly in allografts compared with normal hearts. In addition, an isoform of FGFR1 generated by alternative mRNA splicing that includes the tyrosine kinase domain is expressed in allografts during rejection but is not found in normal hearts. These findings show that transplantation and rejection episodes can modify the usual tissue-specific patterns of alternative mRNA splicing to generate proteins that are not expressed in the normal myocardium, and we postulate that these events may also occur in the larger coronary arteries during the development of CAV.

\section{Methods}

Myocardial biopsies from cardiac allografts and pretransplant normal donor hearts. 20 myocardial biopsies from 20 heart transplant recipients (mean age, $44 \pm 11$ yr old; mean follow-up, 17 $\pm 14 \mathrm{mo}$ ) and 5 biopsies from 5 normal donor hearts before transplantation were analyzed for expression of aFGF and FGF receptor genes by PCR. For controls, myocardium from pretransplant normal donor hearts was obtained from the right ventricle immediately after organ excision. Allograft myocardial biopsies were obtained at the usual routine intervals after transplantation to monitor transplants for histologic rejection and when clinically indicated. Histologic examination and PCR studies on simultaneously obtained biopsies were performed independently. Of the 20 allograft biopsies studied, 14 showed no signs of rejection. Of the remainder, four and two showed mild (grade I) and moderate (grades II and III) rejection, respectively, using criteria established by the International Society for Heart Transplantation. 18 myocardial biopsies from 15 allografts and 3 normal hearts were studied by in situ hybridization and immunohistochemistry (6 rejecting and 9 nonrejecting allografts). One sample was obtained from autopsy material in a patient who died with severe acute rejection. Biopsies were embedded in OCT compound (Miles Laboratories Inc., Elkhart, IN) immediately after biopsy and stored at $-70^{\circ} \mathrm{C}$ until cutting. All patients participating in this study received standard immunosuppression with cyclosporine, azathioprine, and prednisone. The studies were approved by the Institutional Review Board.

Human umbilical vein endothelial cell (HUVEC) culture. HUVECs (Clonetics Corp., San Diego, CA) were grown on gelatin-coated plates in endothelial cell growth medium (EGM; Clonetics Corp.), supplemented with $2 \%$ heat-inactivated FBS, $1 \mu \mathrm{g} / \mathrm{ml}$ hydrocortisone, $50 \mu \mathrm{g} /$ $\mathrm{ml}$ gentamicin, $50 \mu \mathrm{g} / \mathrm{ml}$ amphotericin B, bovine brain extract, and $10 \mathrm{ng} / \mathrm{ml}$ epidermal growth factor. Cultures were expanded by trypsin treatment and subculturing at 1:5 split ratio. Cells from passage 3 or 4 were used in these experiments. After reaching $80 \%$ confluence, to induce quiescence HUVECs were cultured for $72 \mathrm{~h}$ in growth factorfree medium (EBM; Clonetics Corp.), supplemented with 10\% FBS. To test the effects of growth factors and cytokines on FGFR, quiescent cells were treated with recombinant human aFGF $(10 \mathrm{ng} / \mathrm{ml})$, recombi- nant human IL-6 ( $15 \mathrm{ng} / \mathrm{ml})$, TGF- $\beta(1 \mathrm{ng} / \mathrm{ml})$ (all from R\&D Systems, Inc., Minneapolis, MN) or PMA ( $100 \mathrm{ng} / \mathrm{ml}$; Sigma Immunochemicals, St. Louis, MO) for $1,2,4,8$, or $12 \mathrm{~h}$. Heparin $(10 \mathrm{U} / \mathrm{ml})$ was added to medium with aFGF. Cells were harvested directly into lysis buffer for RNA preparation.

Isolation of RNA from myocardial biopsy specimens and HUVECs. Individual biopsies for RT/PCR were placed in sterile freezer vials (Nunc, Roskilde, Denmark) and stored at $-70^{\circ} \mathrm{C}$ until used för RNA preparation. Total RNA was isolated from myocardial biopsy specimens by the guanidinium thiocyanate-phenol chloroform method (30) in 500 $\mu l$ homogenization buffer. The RNA was dissolved in $10 \mu$ l diethyl pyrocarbonate-treated distilled water for reverse transcription reaction. RNA from HUVECs was isolated using Tri-Reagent (MRC, Cincinnati, $\mathrm{OH})$ as suggested by the manufacturer.

$R T$ and PCR. Total RNA isolated from myocardial biopsies, HUVECs, and control cultured human kidney endothelial cells (KEC, kindly provided by Dr. T. O. Daniel, Vanderbilt University) was used as template for cDNA synthesis with oligo dT and MMLV reverse transcriptase (GIBCO BRL, Gaithersburg, MD) as suggested by the manufacturer. For HUVECs and KECs, $2 \mu \mathrm{g}$ of total RNA of each sample was used as template for cDNA synthesis. For myocardial biopsies, the amount of tissue was too small to allow quantitation of RNA, therefore the total yield from each specimen was used as template for cDNA synthesis in a final reaction volume of $25 \mu \mathrm{l}$, and $1 \mu \mathrm{l}$ was used for each PCR. The Oligo program (version 4.0; National Biosciences, Plymouth, MN) was used to design some of the primers used, and others have been reported previously. For FGF receptor 1, five pairs of primers were used so that expression of various FGFR1 transcripts generated by alternative mRNA splicing could be detected (see Table I and Fig. 2). Primer pairs are identified by the extracellular Ig-like domain or kinase domain they amplify. Primers for the second Ig-like domain (primer II) and the antisense primers for exons that generate the alternative second half of the third Ig-like domain (IIIa, IIIb, and IIIc) have been reported previously (24). Primer pairs IIIa, IIIb, and IIIc use the same 5' sense primer, which hybridizes to a sequence in the acidic box, and antisense primers specific for the alternatively spliced exons encoding the second half of the third Ig-like domain. Primer pair $\mathrm{K}$ amplifies cDNA encoding the transmembrane and tyrosine kinase domains. For the remaining FGF receptors (FGFR2, FGFR3, and FGFR4), two pairs of primers were used. Primers designated "I" amplify cDNA encoding the first extracellular Ig-like domain of each receptor. Primers designated " $K$ " amplify cDNA encoding the transmembrane and tyrosine kinase domains (see Table I and Fig. 2). Primers for the constitutively expressed human glyceraldehyde-3-phosphate dehydrogenase gene (GAPDH; Clontech Laboratories, Inc., Palo Alto, CA) were used as a positive control. PCR reactions were performed in $10 \mathrm{mM}$ Tris/ $\mathrm{HCl}, \mathrm{pH} 8.3,50 \mathrm{mM} \mathrm{KCl}, 1.5 \mathrm{mM} \mathrm{MgCl} 2,0.2 \mathrm{mM} \mathrm{dNTP}$, with $2 \mathrm{U}$ of Taq polymerase (Perkin-Elmer Cetus Corp., Norwalk, CT). Primers were added at a final concentration of $0.5 \mu \mathrm{M}$. Reactions were carried out in a DNA Thermal Cycler (Perkin-Elmer Cetus Corp.) for 35 cycles including denaturing at $94^{\circ} \mathrm{C}$ for $1 \mathrm{~min}$, annealing at $48-60^{\circ} \mathrm{C}$ for $1 \mathrm{~min}$, and extension at $72^{\circ} \mathrm{C}$ for $2 \mathrm{~min}$ for each cycle. PCR products were analyzed on $2 \%$ ethidium bromide-stained agarose gels.

Quantitation of mRNA expression. For HUVEC RNA, PCR analyses for each primer pair were performed using cDNA template derived from 80 ng of total RNA. RNA from myocardial biopsies could not be quantitated because of the small size of the biopsies $\left(<1 \mathrm{~mm}^{3}\right)$. Therefore, PCR studies on myocardial biopsies for each primer pair were routinely performed with one-twentyfifth of the total cDNA $(1 \mu \mathrm{l})$. Initial experiments to detect expression of the first extracellular Ig-like domain of FGFR1 showed that this transcript was present in both normal hearts and allografts, but with much greater intensity in PCRs from allografts. Previously described quantitative PCR methods require relatively large amounts of cDNA since multiple PCRs are performed with fixed amounts of cDNA and varying dilutions of competitor. The amount of cDNA from the myocardial biopsies is rather limited, and the competitor approach does not correct for difference in the size of the biopsies. Therefore, the following alternative approach was used. The amount of 
A
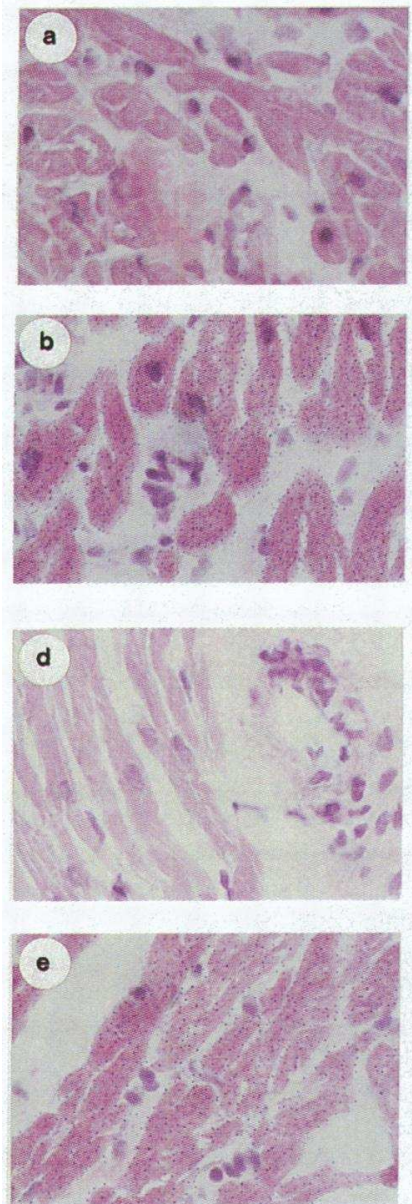
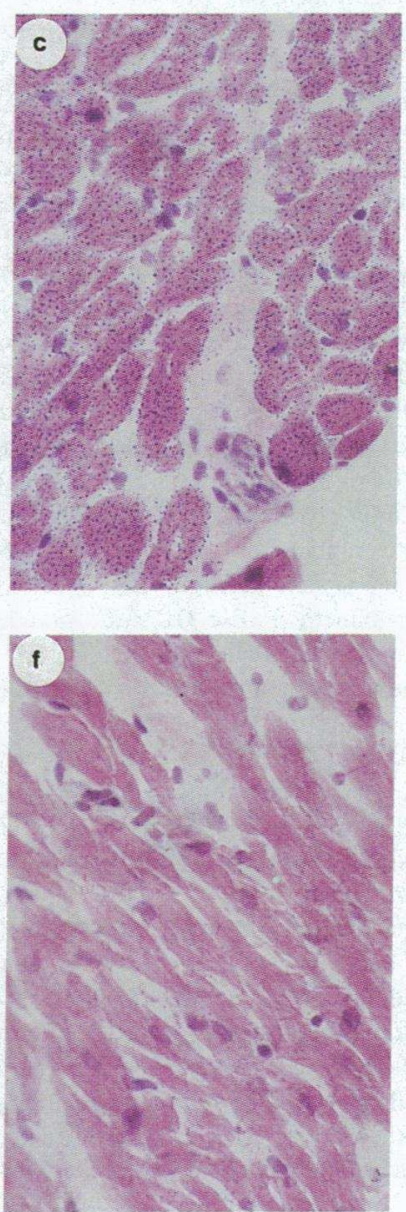

B
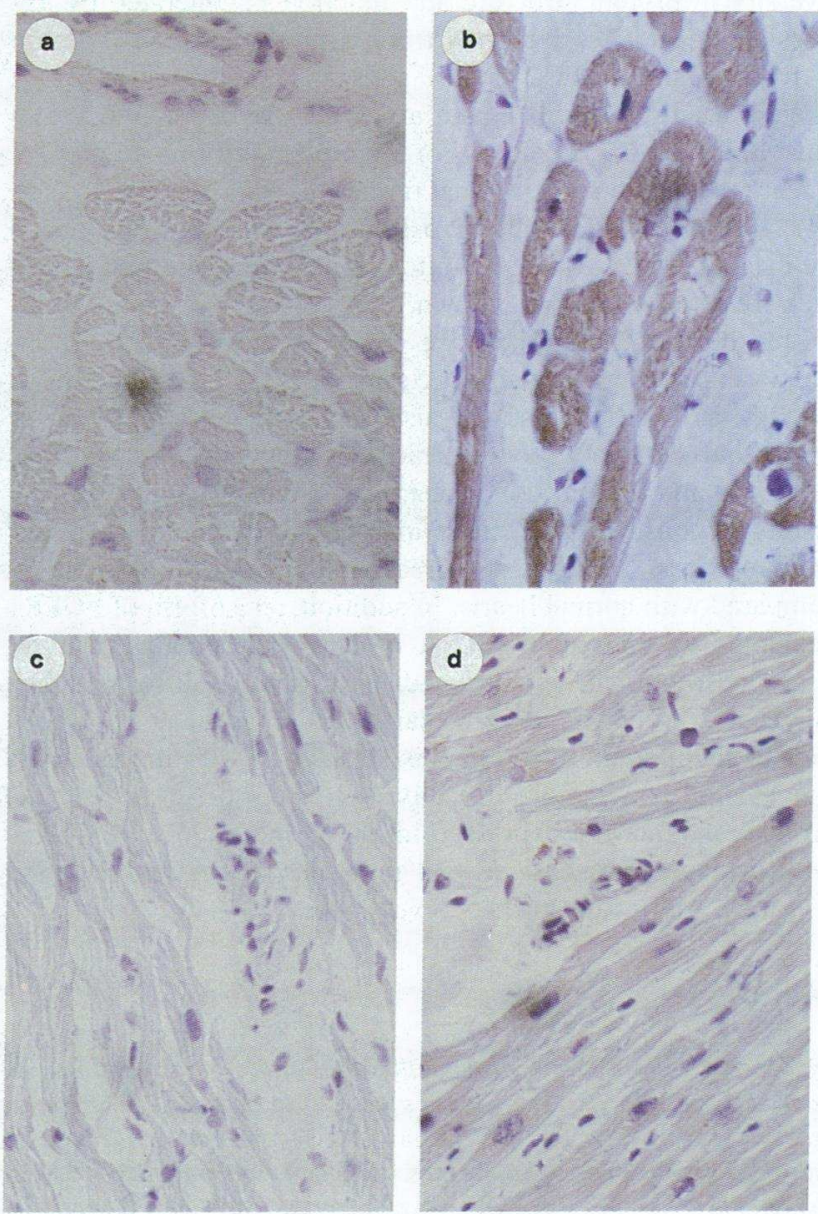

Figure 1. In situ hybridization and immunohistochemistry of myocardial biopsies. $A$ shows in situ hybridization. Upper panels $(a, b$, and $c)$ show biopsy from transplanted heart. Lower panels $(d, e$, and $f$ ) show biopsy from normal heart. $a$ and $d$ are negative controls hybridized with sense probe for GAPDH; $b$ and $e$ are positive controls hybridized with antisense probe for GAPDH; $c$ and $f$ are hybridized with antisense probe for aFGF. All the probes were labeled with digoxigenin, and signals were detected by AP-conjugated antidigoxigenin antibody. Positive hybridization is seen as blue precipitates. $B$ shows immunohistochemistry stain. Upper panels ( $a$ and $b$ ) show biopsy from transplanted heart. Lower panels ( $c$ and $d$ ) show biopsy from normal heirt. $a$ and $c$ are negative controls, stained with peroxidase-conjugated goat anti-mouse IgG antibody alone; $b$ and $d$ are stained with monoclonal anti-aFGF and subsequently with peroxidase-conjugated goat anti-mouse IgG antibody. Positive peroxidase reaction gives a brown color. $\times 100$.

FGFR1 cDNA was normalized to the amount of cDNA for GAPDH in each biopsy. This was done by performing parallel PCRs for the first Ig-like domain of FGFR1 and GAPDH on serial twofold dilutions of cDNA from each biopsy to determine the highest dilution or titer of cDNA yielding a positive PCR for each message (see Fig. 3). Since GAPDH mRNA is expressed constitutively, the highest dilution or titer of GAPDH cDNA reflects the starting mRNA concentration. A numerical value for FGFR1 expression in each biopsy was derived from the ratio of the last dilution giving a positive PCR for FGFR1 divided by the last dilution giving a positive PCR for GAPDH. This value reflects the amount of FGFR1 cDNA present per unit of GAPDH cDNA in each biopsy.

In situ hybridization and immunohistochemistry. Myocardial biopsies used for histology were embedded in OCT compound (Miles Laboratories Inc.) immediately after biopsy and stored at $-70^{\circ} \mathrm{C}$ until cutting. Sections were cut $(6 \mu \mathrm{m})$ and fixed in $3 \%$ paraformaldehyde/PBS. In situ hybridization was performed using the In Situ Workstation (British Bio-technology Products, Abingdon, UK) and solutions as recommended by the manufacturer (21). Briefly, the slides were washed in PBS three times after fixation and incubated in $2 \times \mathrm{SSC}$ at $60^{\circ} \mathrm{C}$ for 10 min. For proteolytic enzyme digestion to expose the target RNA in the section, the slides were incubated with proteinase $\mathrm{K}(1 \mu \mathrm{g} / \mathrm{ml}$; British Bio-technology Products) at $37^{\circ} \mathrm{C}$ for $15 \mathrm{~min}$, and the reaction was stopped by fixing in precooled $0.4 \%$ paraformaldehyde/PBS for 20 min. After fixation, the slides were washed with PBS and subsequently incubated with prehybridization solution containing $0.6 \mathrm{M}$ salt, $30 \%$ formamide, and $150 \mu \mathrm{g} / \mathrm{ml}$ sonicated salmon sperm DNA (British Biotechnology Products) for $2 \mathrm{~h}$. Digoxigenin-labeled probes were added to fresh prehybridization solution $(200 \mathrm{ng} / \mathrm{ml})$, and hybridization was carried out for $16 \mathrm{~h}$ at $37^{\circ} \mathrm{C}$. Probes were single-stranded DNA oligonucleotides labeled by $3^{\prime}$ tailing with digoxigenin-11-dUTP and terminal deoxynucleotide transferase (Boehringer Mannheim Corp., Indianapolis, IN). The oligonucleotide probes used for in situ hybridization were antisense aFGF (5'-cagaagagactggcagggggag) and antisense FGFR1 ( $5^{\prime}$-tgaaacattgacggagaagtaggtg) probes which hybridize to the first Iglike domain and to a sequence in the tyrosine kinase domain ( $5^{\prime}$-gttgtagcagtattccagcc). An antisense probe for GAPDH was used for each sample as a positive control ( $5^{\prime}$-catgtgggccatgaggtccaccac) to ensure that mRNA in myocardial biopsies was intact. A sense probe for GAPDH ( 5 '-tgaaggtcggagtcaacggatttggt) served as the negative control 


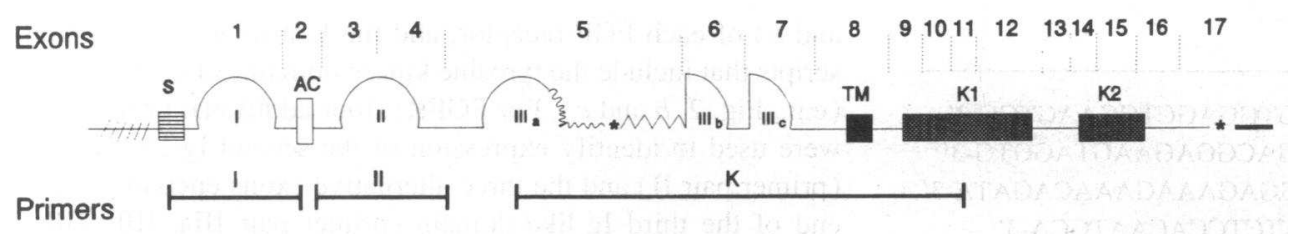

Figure 2. Structure of the human fibroblast growth factor receptors and their alternatively spliced isoforms. $S$, signal peptide; $A C$, acidic box; I, II, III, immunoglobulin-like domains; $T M$, transmembrane region; $K 1, K 2$, kinase domain. Uppermost diagram shows exons contributing to FGFR domains. IIIa is the sequence encoding the alternatively expressed portion of third Ig-like domains which is specific for the secreted FGFR1 (wavy line); IIIb/c are sequences encoding alternatively expressed portion of third Ig-like domain for membrane-spanning FGFR 1 isoforms; TM, transmembrane portions; $K 1, K 2$, kinase domain. $a$, secreted form of FGFR 1 including IIIa, wavy line indicates sequence IIIa specific to secreted forms of FGFR $1 ; b$, full length

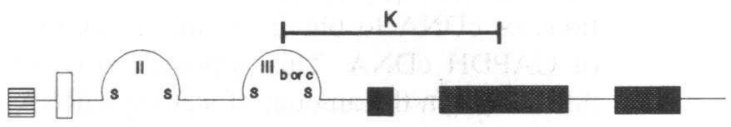

transmembrane FGFR1 with three extracellular Ig-like domains and functional tyrosine kinase domain; $c$, two Ig-like domain transmembrane forms with functional tyrosine kinase domain; amplified PCR products are indicated. Primer I amplifies the signal peptide sequence and first Ig-like domain of FGFR1; primer II amplifies the second Ig-like domain of FGFR1; primer IIIa amplifies mRNA encoding the sequence of third Ig-like domain which is specific for secreted FGFR1 forms; primer IIIb and IIIc amplify mRNA encoding the sequences which are alternatively expressed in membrane-spanning forms of FGFR1; primer $\mathrm{K}$ amplifies the transmembrane and intracellular tyrosine kinase domains of FGFR. This figure is modified from reference 23 .

to demonstrate that hybridization was specific for RNA, and DNA was not being detected. After hybridization, slides were washed sequentially with 4,2 , and $0.2 \times$ SSC, all containing $30 \%$ formamide at $37^{\circ} \mathrm{C}$, and then with $0.1 \%$ Triton $\mathrm{X}-100 / \mathrm{TBS}$. The slides were equilibrated in Genius buffer 1 ( $150 \mathrm{mM} \mathrm{NaCl}, 100 \mathrm{mM}$ Tris, pH 7.5) (Boehringer Mannheim Corp.) for $5 \mathrm{~min}$ and blocked with Genius buffer 2 (150 $\mathrm{mM} \mathrm{NaCl}, 100 \mathrm{mM}$ Tris, pH 7.5, $2 \%$ blocking reagent; Boehringer Mannheim Corp.) for 30 min. Alkaline phosphatase-conjugated sheep polyclonal anti-digoxigenin Fab fragments $(1.5 \mathrm{U} / \mathrm{ml}$ in Genius buffer 2; Boehringer Mannheim Corp.) were used to detect digoxigenin-labeled probes. The slides were incubated with antibody for $2 \mathrm{~h}$ and washed with Genius buffer 1 . The slides were equilibrated in Genius buffer 3 ( $100 \mathrm{mM}$ Tris, $\mathrm{pH} 9.5,100 \mathrm{mM} \mathrm{NaCl}, 50 \mathrm{mM} \mathrm{MgCl}$ ) for $5 \mathrm{~min}$ and then incubated with NBT/X-phosphate substrate overnight to detect the color change (nitroblue tetrazolium, $340 \mathrm{ng} / \mathrm{ml}$ in Genius buffer 3 plus 5-bromo-4-chloro-3-indolyl phosphate toluidinium, $180 \mathrm{ng} / \mathrm{ml}$; Boehringer Mannheim Corp.) and subsequently counterstained with hematoxylin-eosin. Positive hybridization appears as a blue precipitate.

For immunohistochemistry staining, samples were initially processed as described above. After cutting and fixing, slides were treated with 3\% hydrogen peroxide/methanol for $20 \mathrm{~min}$ and then washed with PBS. After 30 min of blocking with $5 \%$ BSA, slides were incubated with anti-aFGF ( $15 \mu \mathrm{g} / \mathrm{ml}$ in $1 \%$ BSA/TBS) or anti-FGFR1 (1:100) for $2 \mathrm{~h}$ at room temperature. The antibodies used for these studies were mouse monoclonal anti-aFGF (UBI, Lake Placid, NY), mouse monoclonal antibody directly against the first Ig-like domain of FGFR1 (M2F12, kindly provided by Dr. Wallace McKeehan, Texas A and M University, Houston, TX) (31), and rabbit polyclonal antibody to the carboxy terminus of the tyrosine kinase domain of FGFR1 (E22K, a gift from Dr. McKeehan) (31). After incubation and washing with PBS, slides were then incubated with peroxidase-conjugated second antibody (goat anti-mouse IgG, 1:200 in 1\% BSA/TBS [UBI], or goat antirabbit IgG, 1:500 dilution [Southern Biotechnology, Birmingham, AL]) and subsequently stained with 3,3'-diaminobenzidine (Sigma Immunochemicals) followed by counterstaining with hematoxylin.

Statistical analysis. Receptor gene expression in cardiac allografts and normal donor hearts was compared by Wilcoxon rank test. Correla- tion of receptor gene expression with histological rejection and growth factor gene expression was analyzed by Fisher's exact test.

\section{Results}

Expression of aFGF $m R N A$ and protein in cardiac allografts. aFGF is a potent mitogen for SMC and EC. Our previous studies using PCR have shown that expression of aFGF is markedly increased in cardiac allografts and that human $T$ cells can produce aFGF $(20,21)$. These results were confirmed using in situ hybridization (Fig. $1 A$ ) and immunohistochemistry (Fig. $1 B$ ). Positive controls with an antisense probe for GAPDH show that mRNA is intact in biopsies from a cardiac allograft and normal donor heart (Fig. $1 A$, panels $b$ and $e$ ). Negative controls with a sense probe for GAPDH demonstrate that hybridization is specific for RNA (Fig. $1 A$, panels $a$ and $d$ ). Hybridization with an antisense aFGF oligonucleotide shows strong hybridization in the allograft biopsy (Fig. $1 A$, panel $c$ ) with little or no aFGF mRNA detected in the normal heart (Fig. $1 A$, panel $f$ ). aFGF is found in myocytes, vessel walls, and infiltrating mononuclear cells (data not shown). Immunohistochemistry (Fig. $1 B$ ) confirmed that expression of aFGF mRNA (Fig. $1 A$ ) results in markedly increased production of aFGF protein in cardiac allografts compared with normal hearts (Fig. $1 B$, panel $b$ versus panel $d$ ).

Expression of FGF receptor genes in cardiac allografts. FGFs act by binding to high-affinity plasma membrane receptors (22). Therefore, the finding that aFGF expression was rapidly and stably increased after transplantation prompted us to examine the expression of receptors that bind aFGF. Four genes belonging to the FGF receptor family have been identified in human tissues (FGFR1, FGFR2, FGFR3, and FGFR4) (22, 32-36). FGFR1 and FGFR2 are expressed as multiple isoforms 
Table I. Primers Used for PCR*

\begin{tabular}{|c|c|c|}
\hline \multirow[t]{12}{*}{ FGFR1 } & & 5'-ATTCGGGATGTGGAGCTGGAAGTGC-3' \\
\hline & \multirow[t]{2}{*}{ I } & 5'-TGAAACATTGACGGAGAAGTAGGTG-3' \\
\hline & & 5'-CTCTTCAGAGGAGAAAGAAACAGATA-3' \\
\hline & \multirow[t]{2}{*}{ II } & 5'-CCGTACTCATTCTCCACAATGCA-3' \\
\hline & & 5'-CTCTTCAGAGGAGAAAGAAACAGATA-3' \\
\hline & \multirow[t]{2}{*}{ IIIa } & 5'-GACTGGCCCACGAAGACTGGTGCCAT-3' \\
\hline & & 5'-CTCTTCAGAGGAGAAAGAAACAGATA-3' \\
\hline & \multirow[t]{2}{*}{ IIIlb } & 5'-TCTGGTGACAGTGAGCCA-3' \\
\hline & & 5'-CTCTTCAGAGGAGAAAGAAACAGATA-3' \\
\hline & \multirow[t]{2}{*}{ IIIc } & 5'-CATCTCTTTGTCGGTGGTATTAACTCCA-3' \\
\hline & & 5'-GACAAAGAGATGGAGGTGCT-3' \\
\hline & $\mathbf{K}$ & 5'-GTTGTAGCAGTATTCCAGCC-3' \\
\hline \multirow[t]{4}{*}{ FGFR2 } & \multirow{3}{*}{ I } & 5'-GGTCGTTTCATCTGCCTGGT-3' \\
\hline & & 5'-CCTTCCCGTTTTTCAGCCAC-3' \\
\hline & & 5'-GTCCATCAATCACACGTACCACCTG-3' \\
\hline & $\mathbf{K}$ & 5'-AATCATCTTCATCATCTCСАТСТСТ-3' \\
\hline \multirow[t]{4}{*}{ FGFR3 } & \multirow{3}{*}{ I } & 5'-GGGGCCCACTGTCTGGGTCAAG-3' \\
\hline & & 5'-GTCTTCGTCATCTCCCGAGGAT-3' \\
\hline & & 5'-GCAGCATCCGGCAGACGTACAC-3' \\
\hline & $\mathbf{K}$ & 5'-GGCGGCCCGGTCCTTGTCAATG-3' \\
\hline \multirow[t]{4}{*}{ FGFR4 } & \multirow{3}{*}{ I } & 5'-CCTGTTGGGGGTCCTGCTGAGTGTG-3' \\
\hline & & 5'-CTTGCTGGGGGTAACTGTGCCTATT-3' \\
\hline & & 5'-GGCAGCATCCGCTATAACTACC-3' \\
\hline & $\mathbf{K}$ & 5'-GCCACAGTGCTGGCTTGGTCAG-3' \\
\hline
\end{tabular}

* For each pair, the $5^{\prime}$ sense primer is listed first.

generated by alternative mRNA splicing (22-27). As shown in Fig. 2, full length FGFR1 is comprised of a signal peptide, three extracellular Ig-like domains, transmembrane, and intracellular tyrosine kinase domains (Fig. $2 b$ ). Three alternative exons encoding the second half of the third Ig-like domain (IIIa, IIIb, and IIIc) have been identified in genomic DNA. Usage of one of these alternative exons (exon 5, encoding IIIa) results in a secreted form of FGFR1 (Fig. $2 a$ ). Inclusion of either exon 6 (encoding IIIb) or exon 7 (encoding IIIc) in the FGFR1 transcript results in transmembrane forms of FGFR1 that presumably also include kinase domains capable of signal transduction (Fig. 2, b and c). Both IIIb and IIIc variants bind aFGF with high affinity, although receptor isoforms with IIIb have a 50-fold lower affinity for basic FGF than does the IIIc form $(24,25)$. In addition, isoforms containing one and two Ig-like domains (Fig. $2 c$ ) have been reported (22). The extracellular domains are responsible for ligand binding, specificity, and affinity, while the intracellular tyrosine kinase domain is required for signal transduction and mitogenesis. Expression of FGFR isoforms varies in different tissues and with different members of the FGFR family $(28,29)$. Normal hearts have been reported to express isoforms of FGFR1 containing only extracellular domains (e.g., Fig. $2 a$ ) while skin and some tumor cells express isoforms with both extracellular and intracellular domains (e.g., Fig. 2, $a-c)(28)$.

In the following experiments, two pairs of primers (I and K, Table I, Fig. 2) were used for each of the four FGF receptor genes (FGFR1-4) to detect expression of isoforms with and without kinase domains. The I primers detect transcripts that include the first extracellular Ig-like domains (e.g., Fig. 2, a and $b$ ) of each FGF receptor, and the K primers amplify transcripts that include the tyrosine kinase domains of each receptor (e.g., Fig. 2, $b$ and $c$ ). For FGFR1, four additional primer pairs were used to identify expression of the second Ig-like domain (primer pair II) and the three alternative exons encoding the $3^{\prime}$ end of the third Ig-like domain (primer pair IIIa, IIIb, IIIc). All of the primer pairs span at least one intron and therefore do not amplify genomic DNA (Fig. 2).

Preliminary experiments (not shown) using primer I for FGFR1 (FGFR1-I) demonstrated that transcripts encoding the first extracellular Ig-like domain of FGFR1 were detected in both allografts and normal donor hearts. However, the bands in PCRs from allografts were much brighter than those with normal hearts, suggesting there were quantitative differences in expression of this mRNA. Therefore, the amount of FGFR1-I cDNA was compared with the amount of GAPDH cDNA present in each biopsy by performing PCRs on serial twofold dilutions of cDNA to obtain a ratio of FGFR1-I cDNA per unit of GAPDH cDNA. This approach also corrects for potential differences in the amount of starting mRNA due to differences in the size of the biopsies. An example of such a titration using primers for FGFR1-I and GAPDH is shown in Fig. 3. In this biopsy, a final dilution of 1:32 of the starting cDNA yielded the last positive PCR for both GAPDH and FGFR1-I cDNA amplified by primer I, giving a ratio of 1 . Similar titrations were performed for the remaining biopsies as shown in Table II (column 5). There was a 35-fold increase in FGFR1-I transcripts in allografts compared with normal donor hearts while the amounts of GAPDH cDNA were not significantly different in allograft biopsies compared with biopsies from normal donor hearts $(P=0.75)$. The mean FGFR1-I/GAPDH ratio was $2.41 \pm 2.02$ in allograft myocardial biopsies and $0.07 \pm 0.04$ in pretransplant hearts $(P<0.001$, Wilcoxon rank test) (Table II, column 5). There was no correlation between the FGFR1I/GAPDH ratio and diagnosis of histological rejection.

As shown in Fig. 2, alternative splicing of FGFR1 may lead to transcripts that either include (Fig. 2, $a$ and $b$ ) or lack (Fig. $2 c$ ) the first Ig-like domain detected by PCR with primer I. However, most isoforms of FGFR1 are believed to include the second Ig-like domain. PCRs with primer II to detect expression of transcripts including the second Ig-like domain were positive in all of the normal hearts and in 19 of the 20 allografts tested (Fig. 4, FGFR1 (II), and Table II, column 6). These results are consistent with the data presented above that show expression of transcripts including FGFR1-I in all biopsies. As we had observed initially with the PCRs using primer I for FGFR1, PCRs with primer II also showed that the bands with cDNA from allografts were considerably brighter than those found with cDNA from normal hearts. The greater intensity of PCR bands found for the second Ig-like domain suggests that transcripts including this domain are also increased in allografts compared with normal hearts.

Alternative usage of exons encoding the $3^{\prime}$ half of the third Ig-like domain determines whether the transcript results in a secreted form of FGFR1 or one that is anchored in the membrane and potentially capable of mediating the actions of aFGF via the kinase domain (Fig. 2). PCRs were performed with primer pairs specific for each of these exons and the kinase domain of FGFR1 (Fig. 4, rows 2-5). Transcripts encoding the secreted form of FGFR1 were present in 19 of 20 allografts and in all 5 normal hearts (primer II/IIIa, Fig. 4, and Table II, column 7). In contrast, transcripts including the transmembrane 


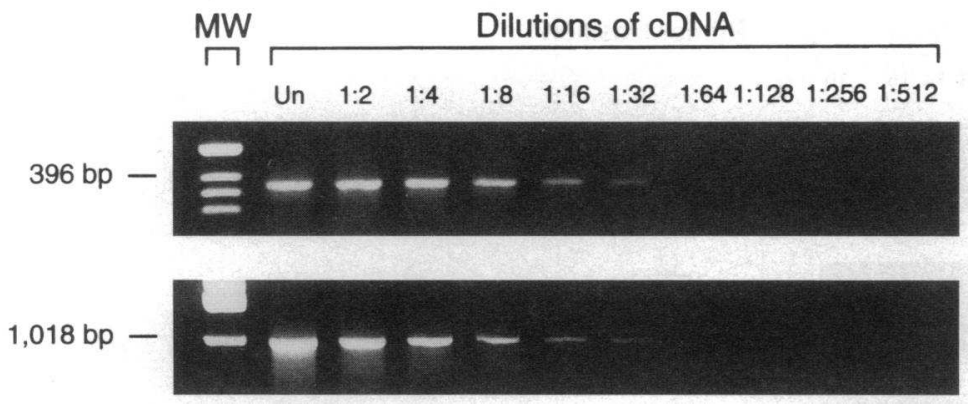

Figure 3. Quantification of FGFR1 mRNA in myocardial biopsies. Representative agarose gel electrophoresis of parallel PCRs for the extracellular first Ig-like domain of FGFR1 (FGFR1-I) and GAPDH on serial twofold dilutions of cDNA from an allograft biopsy. A numerical value for FGFR1-I expression per unit of GAPDH cDNA in each biopsy was obtained from the ratio of the last dilution giving a positive PCR for FGFR1I divided by the last dilution giving a positive PCR for GAPDH. Un, undiluted cDNA; FGFRI (I), extracellular first Ig-like domain of FGFR1; position of the primers used in PCR is indicated.

forms of the third Ig-like domain were detected only in allografts (primers II/IIIb and II/IIIc, Fig. 4, and Table II, columns 8 and 9). mRNAs including IIIc were found in 8 of 20 allo- grafts, and 6 of these were biopsies showing rejection. Transcripts including IIIb were found in 5 of 20 allografts, 3 with rejection and 2 without. Transcripts that include the kinase do-

Table II. FGF Receptor Gene Expression in Cardiac Allografts and Pretransplant Hearts

\begin{tabular}{|c|c|c|c|c|c|c|c|c|c|}
\hline \multirow[b]{2}{*}{ Patient number } & \multirow[b]{2}{*}{ Age } & \multirow[b]{2}{*}{$T x^{*}$} & \multirow[b]{2}{*}{ Rjxn $^{\ddagger}$ grade } & \multirow[b]{2}{*}{ FGFR $1-I^{8}$ GAPDH } & \multicolumn{5}{|c|}{ FGFR1 } \\
\hline & & & & & II & IIIa & IIIJ & IIIc & $\mathbf{K}$ \\
\hline & $y r$ & mo & & & & & & & \\
\hline 1 & 16 & 40 & 0 & $4.00(256 / 64)^{\S}$ & + & + & - & - & - \\
\hline 2 & 14 & 48 & IB & $0.13(2 / 16)$ & + & + & + & + & + \\
\hline 3 & 53 & 5 & 0 & $2.00(128 / 64)$ & + & + & - & - & - \\
\hline 4 & 14 & 72 & 0 & $4.00(128 / 32)$ & + & + & + & + & - \\
\hline 5 & 59 & 58 & 0 & $2.00(32 / 16)$ & + & + & - & _- & - \\
\hline 6 & 59 & 11 & 0 & $4.00(64 / 16)$ & + & + & + & - & - \\
\hline 7 & 46 & 35 & 0 & $2.00(16 / 08)$ & + & + & - & - & - \\
\hline 8 & 50 & 64 & 0 & $4.00(64 / 16)$ & + & + & - & + & - \\
\hline 9 & 56 & 40 & 0 & $4.00(64 / 16)$ & + & + & - & - & - \\
\hline 10 & 39 & 24 & 0 & $0.25(2 / 8)$ & - & - & - & - & - \\
\hline 11 & 35 & 6 & 0 & $1.00(32 / 32)$ & + & + & - & - & - \\
\hline 12 & 53 & 33 & 0 & $4.00(64 / 16)$ & + & + & - & - & - \\
\hline 13 & 49 & 20 & 0 & $1.00(16 / 16)$ & + & + & - & - & - \\
\hline 14 & 18 & 5 & IB & $0.50(16 / 32)$ & + & + & - & + & + \\
\hline 15 & 13 & 70 & IA & $1.00(16 / 16)$ & + & + & - & + & + \\
\hline 16 & 12 & 10 & IIA & $4.00(64 / 16)$ & + & + & + & + & + \\
\hline 17 & 50 & 8 & IA & $1.00(16 / 16)$ & + & + & - & + & - \\
\hline 18 & 55 & 14 & 0 & $8.00(128 / 16)$ & + & + & - & - & - \\
\hline 19 & 45 & 8 & IB & $1.00(64 / 64)$ & + & + & + & + & + \\
\hline 20 & 50 & 9 & 0 & $0.25(8 / 32)$ & + & + & - & - & - \\
\hline Mean & $39 \pm 33$ & $29 \pm 45$ & & $2.41 \pm 2.02^{\| \prime}$ & $19 / 20^{4}$ & $19 / 20^{4}$ & $5 / 20^{1}$ & $8 / 20^{4}$ & $5 / 20^{9}$ \\
\hline 1 & PreTx** & & & $0.06(1 / 16)$ & + & + & - & - & - \\
\hline 2 & PreTx & & & $0.13(8 / 64)$ & + & + & - & - & - \\
\hline 3 & PreTx & & & $0.02(2 / 32)$ & + & + & - & - & - \\
\hline 4 & PreTx & & & $0.02(2 / 128)$ & + & + & - & - & - \\
\hline 5 & PreTx & & & $0.06(2 / 32)$ & + & + & - & - & - \\
\hline Mean & & & & $0.07 \pm 0.04^{\|}$ & $5 / 5^{9}$ & $5 / 5^{9}$ & $0 / 5^{9}$ & $0 / 5^{9}$ & $0 / 5^{1}$ \\
\hline
\end{tabular}

$\| P<0.001$ (Wilcoxon rank test). ${ }^{8}$ FGFR1-I/GAPDH is the ratio of FGFR1-I cDNA relative to cDNA for GAPDH as described in Methods and Fig. 3. Numbers in parentheses are last dilution of cDNA yielding a positive PCR for FGFR1-I/last dilution yielding a positive PCR for GAPDH. * Months after heart transplantation. ${ }^{\ddagger}$ Histological rejection on simultaneously obtained biopsy. ' Number of biopsies positive for gene expression. ** Biopsies from normal donor hearts before transplantation. 


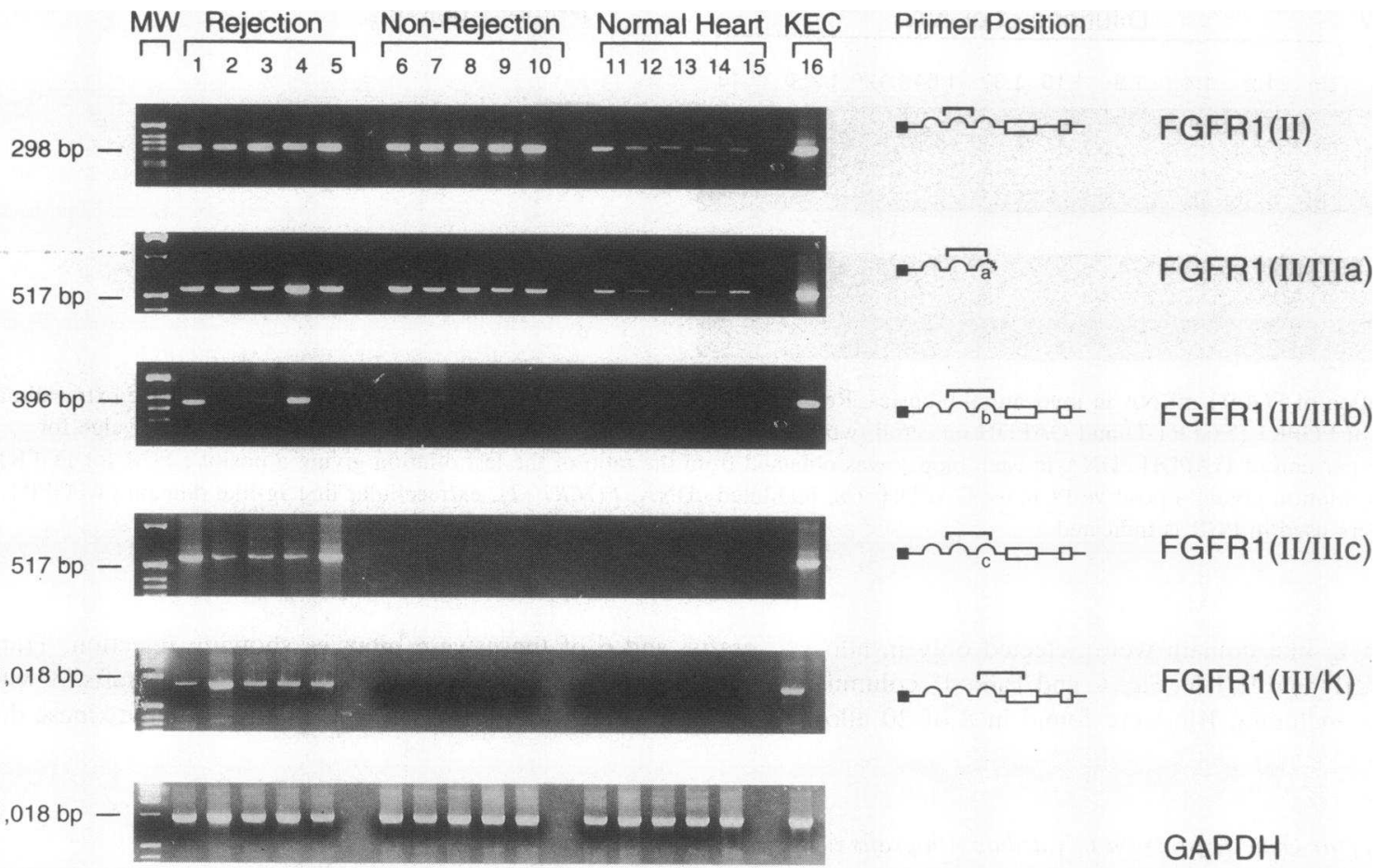

Figure 4. Expression of FGFR1 isoforms in myocardial biopsies. Representative agarose gel electrophoresis of RT/PCR from myocardial biopsies. Position of each primer pair is indicated at the right. PCR products amplified with different primers from the same biopsy are displayed in the same lane from top to bottom. Lane $M W$, DNA molecular weight marker; lanes 1-5, myocardial biopsies with histological rejection; lanes 6-10, myocardial biopsies without histological rejection; lanes $11-15$, myocardial biopsies obtained from normal donor hearts before transplantation; lane 16, positive control KEC; FGFRI (II), second extracellular Ig-like domain of FGFR1; FGFRI (II/IIIa), amplifies sequence present in the third Ig-like domain of secreted form of FGFR1; FGFRI (II/IIIb), amplifies sequence encoding alternative third Ig-like domain (IIIb) in membranespanning form of FGFR 1; FGFRI (II/IIIc), amplifies cDNA encoding alternative third Ig-like domain (IIIc) in membrane-spanning form of FGFR1; FGFRI; (III/K), amplifies cDNA encoding transmembrane and intracellular tyrosine kinase domains of FGFR1.

main also were found only in allograft biopsies, and all of these were from patients with acute rejection (primer K, Fig. 4, Table II, column 10). Positive PCRs for the kinase domain were always associated with a positive PCR for one or both transmembrane forms of the third Ig-like domain, although some PCRs positive for IIIb or IIIc did not amplify with primer pair $\mathrm{K}$. Thus, secreted forms of FGFR1 were present in normal hearts as well as allografts, while transmembrane forms of FGFR1 were found only in allografts, and detection of the kinase domain was correlated with rejection.

Three other members of the FGF receptor family that bind aFGF have been cloned (FGFR2-FGFR4), and their expression in cardiac allografts was also studied in these experiments. Primers amplifying the first extracellular Ig-like domains (primer I) and intracellular tyrosine kinase domains (primer K) were designed for each receptor based on published sequences $(32,35,36)$. Transcripts encoding the first extracellular Ig-like domain of FGFR3 (FGFR3-I) were detected in 17 of 20 allograft biopsies and in 3 of 5 normal donor hearts (data not shown ). There was no significant difference in FGFR3-I expression between allografts and normal hearts $(P=0.2$, Fisher's exact test). Transcripts encoding the tyrosine kinase domain of FGFR3 were not identified in either allografts or normal hearts. FGFR2 and FGFR4 mRNAs were not found in either normal hearts or allografts using these techniques (data not shown).

Detection of FGFR1 isoforms in cardiac allografts by in situ hybridization and immunohistochemistry. We next investi- gated the cell types expressing FGF receptor 1 isoforms using in situ hybridization and immunohistochemistry. Tissues from 15 cardiac allografts ( 6 rejecting and 9 nonrejecting) and 3 biopsies from normal donor hearts were hybridized with 2 oligonucleotide probes for FGFR1 to detect expression of FGFR1 isoforms. Probe I hybridizes to mRNA encoding the first Iglike domain, and probe $\mathrm{K}$ is complementary to a sequence in the tyrosine kinase domain. Sense and antisense probes for GAPDH were used as negative and positive controls, respectively.

The results are shown in Fig. 5. Negative (Fig. $5 \mathrm{~A}$, panels $a$ and $d$ ) and positive (Fig. $5 A$, panels $b$ and $e$ ) control hybridizations were similar in biopsies from allografts (Fig. $5 \mathrm{~A}$, panels $a$ and $b$ ) and normal hearts (Fig. $5 \mathrm{~A}$, panels $d$ and $e)$. Hybridization with probes for FGFR1 demonstrated that expression of mRNA encoding the first extracellular Ig-like domain of FGFR1 was markedly increased in the majority of cardiac allografts (Fig. $5 A$, panel $c$ ), but minimal in normal hearts (Fig. $5 A$, panel $f$ ). These results are consistent with the quantitative analysis by PCR showing a 35 -fold increase in cardiac allografts of mRNA transcripts that include the first Iglike domain (Table II). In allograft biopsies, the distribution and intensity of FGFR1 isoforms detected by the I probe were similar in biopsies from rejecting and nonrejecting hearts. In contrast, higher levels of mRNA encoding the tyrosine kinase domain of FGFR1 were present in rejecting biopsies compared with nonrejecting biopsies (Fig. $5 B$, panel $b$, rejecting, and $a$, nonrejecting). In the nonrejecting biopsy (Fig. $5 B$, panel $a$ ), 
A
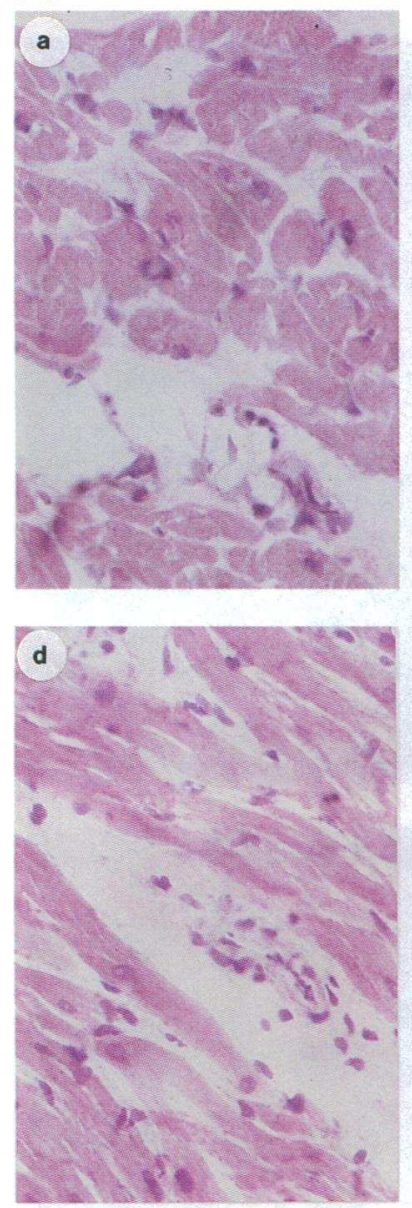
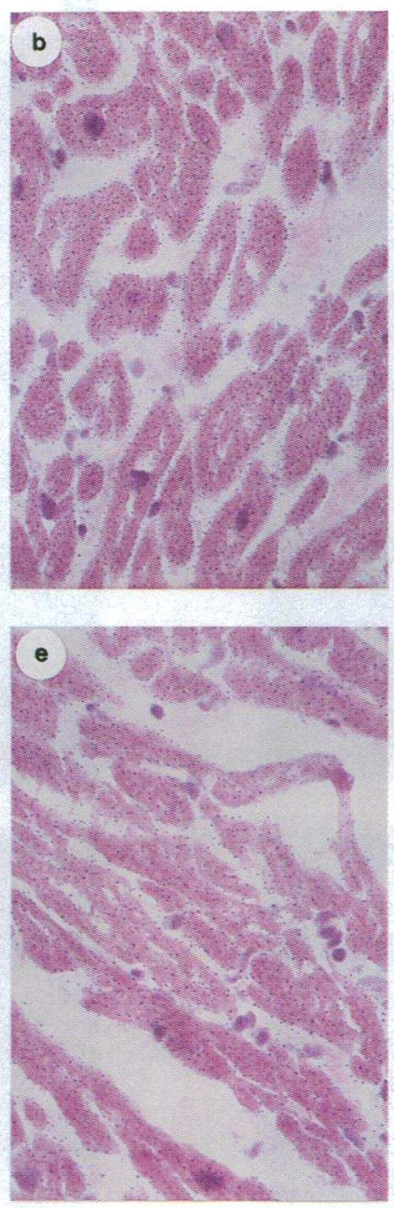
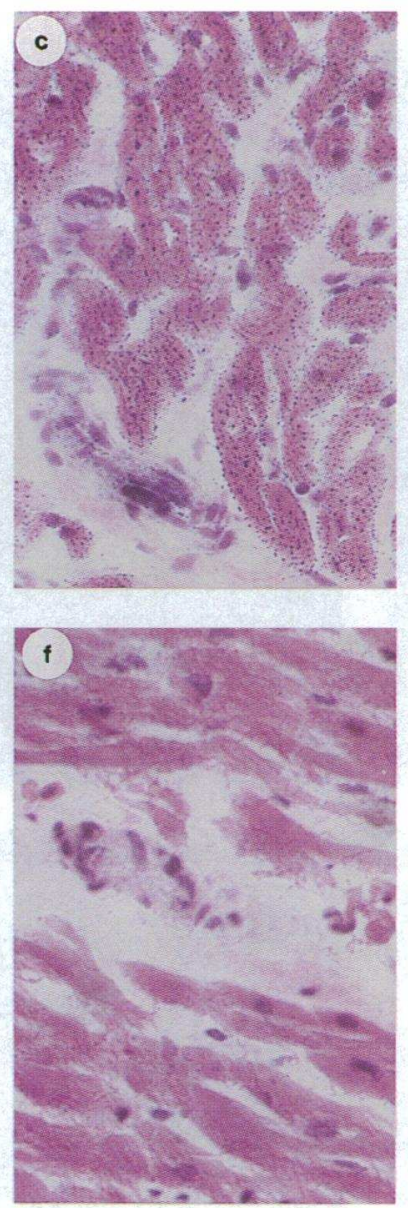

B
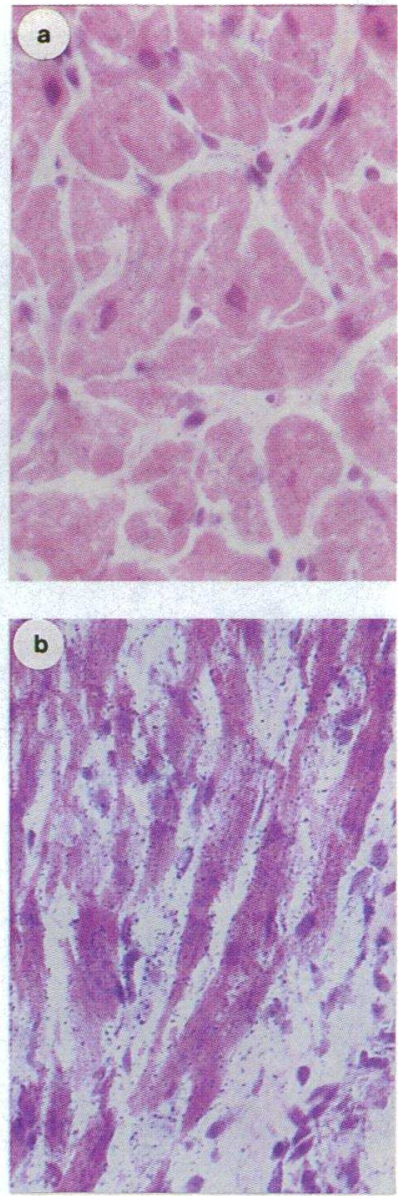

Figure 5. In situ hybridization of FGFR1 mRNA in myocardial biopsies. $A$ shows in situ hybridization of first extracellular Ig-like domain of FGFR1. Upper panels $(a, b$, and $c$ ) show biopsy from transplanted heart (nonrejecting). Lower panels $(d, e$, and $f$ ) show biopsy from normal heart. $a$ and $d$ are negative controls hybridized with sense probe for GAPDH; $b$ and $e$ are positive controls hybridized with antisense probe for GAPDH; $c$ and $f$ are hybridized with antisense probe for the first extracellular Ig-like domain of FGFR1. $B$ shows in situ hybridization for intracellular tyrosine kinase domain of FGFR1. $a$ shows nonrejecting allograft biopsy hybridized with antisense probe for the intracellular tyrosine kinase domain of FGFR $1 ; b$ shows rejecting biopsy hybridized as for $a$. All probes were labeled with digoxigenin, and signals were detected by AP-conjugated antidigoxigenin antibody. $\times 100$.

virtually no hybridization was seen with probe $\mathrm{K}$ for the kinase domain, while in the rejecting biopsy hybridization was markedly increased and was found in yascular structures, infiltrating cells, and cardiac myocytes (Fig. $5 B$, panel $b$ ). mRNA encoding tyrosine kinase-containing isoforms was not detected by in situ hybridization in normal hearts (data not shown).

Expression of FGF receptor 1 protein was confirmed by immunohistochemistry. Two antibodies, M2F12, directed at the first extracellular Ig-like domain, and E22K, recognizing the carboxy terminus of the tyrosine kinase domain (31), were used. The results are shown in Fig. 6. Controls with second antibody alone were negative for both the allograft (Fig. $6 \mathrm{~A}$, panel $a$ ) and the normal heart (Fig. $6 A$, panel $c$ ). Expression of the first Ig-like domain of FGFR1 was increased in the majority of cardiac allografts compared with normal hearts (Fig. 6 $A$, panel $b$ versus panel $d$ ). As seen previously by in situ hybridization, increased expression of tyrosine kinase-containing isoforms of FGFR1 was found in rejecting biopsies compared with nonrejecting biopsies (Fig. $6 B$, panel $b$ versus panel $a$ ).
Regulation of FGF receptor gene expression by aFGF and cytokines expressed during cardiac allograft rejection. The experiments described above demonstrated that expression of aFGF and secreted forms of its receptor, FGFR1, is rapidly increased in human hearts after transplantation. In addition, rejection episodes result in further alterations in expression of this receptor, with production of transmembrane kinase-containing isoforms that are not found in normal hearts. We found previously that IL- 6 and TGF- $\beta$ are induced in cardiac allografts during rejection $(20,37)$, suggesting that these molecules might be involved in the regulation of alternative splicing of FGFR1 that occurs during rejection. Since vessel walls in cardiac allografts show increased expression of aFGF and FGFR1 isoforms (Figs. 1, 5, and 6), we used HUVECs in an in vitro system to examine regulation of FGF receptor expression by IL-6 and TGF- $\beta$.

We found that HUVECs cultured in usual growth factorcontaining medium express all of the known FGF receptors, including tyrosine kinase-containing isoforms of FGFR1 and 

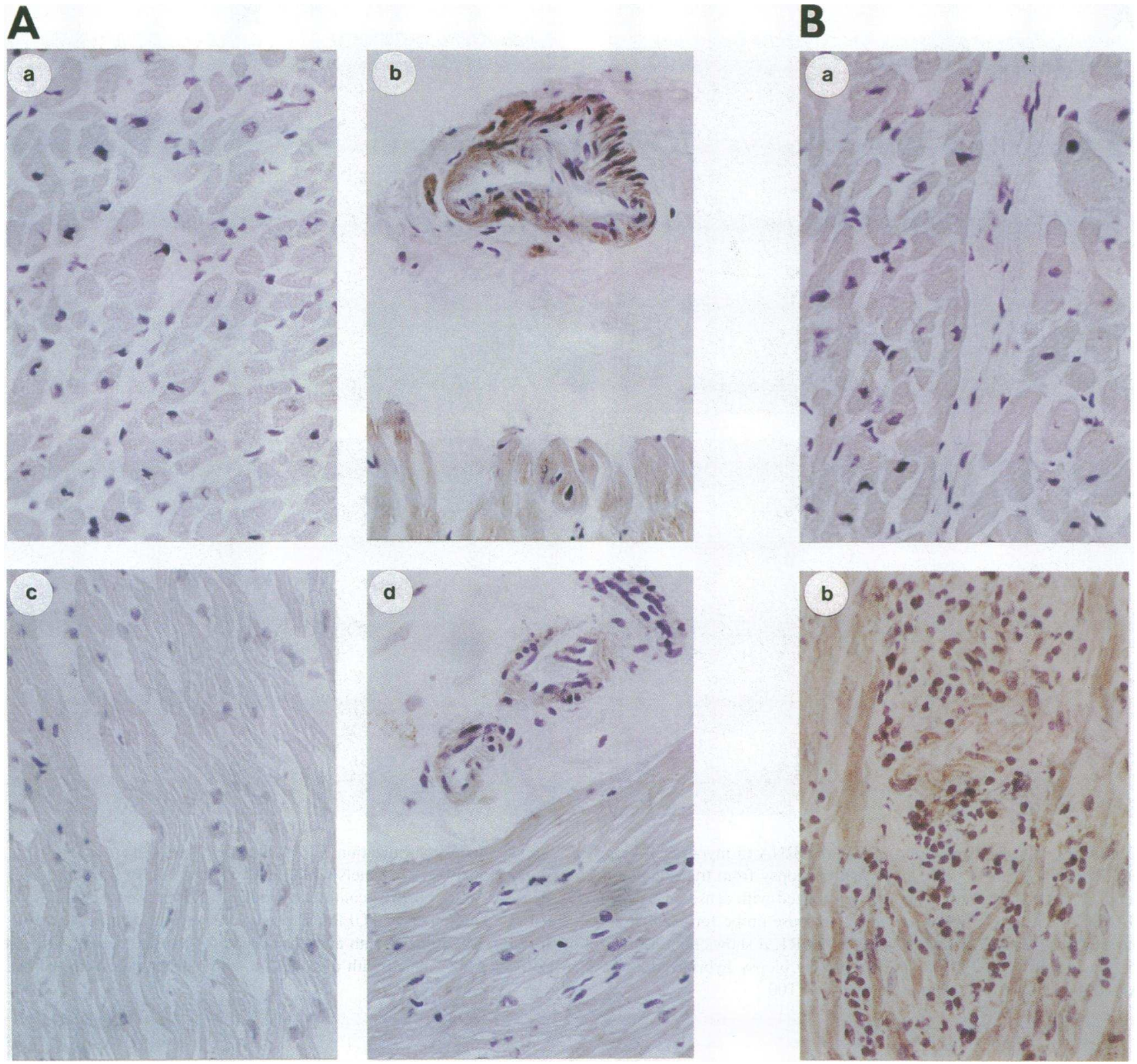

Figure 6. Immunohistochemistry studies for FGFR1. A shows immunohistochemistry stain for extracellular portion of FGFR1. Upper panels ( $a$ and $b$ ) show biopsy from transplanted heart (nonrejecting). Lower panels ( $c$ and $d$ ) show biopsy from normal heart. $a$ and $c$ are negative controls stained with peroxidase-conjugated second antibody alone; $b$ and $d$ are stained with monoclonal antibody against first Ig-like loop of FGFR1 (M2F12) and subsequently stained with peroxidase-conjugated second antibody. $B$ shows immunohistochemistry stain for intracellular portion of FGFR1. $a$ shows nonrejecting allograft biopsy, and $b$ shows rejecting biopsy stained with antibody against carboxy terminus of tyrosine kinase domain of FGFR1 (E22K) and subsequently stained with peroxidase-conjugated antibody. $\times 100$.

FGFR4 (data not shown). Therefore, to study the effects of aFGF, IL-6, and TGF- $\beta$ on resting cells, the HUVECs were rendered quiescent by culture in growth factor-free medium for $72 \mathrm{~h}$ as described in Methods. Cells cultured in this manner were viable and expressed only low levels of FGFR1 and FGFR3 transcripts that included the first Ig-like domains but not the kinase domains (Fig. 7, and data not shown). Quiescent HUVECs were treated with aFGF, IL-6, TGF- $\beta$, or PMA as a positive control, for the indicated times and analyzed for FGFR gene expression by RT/PCR. The results are shown in Fig. 7. aFGF rapidly induced expression of FGFR1 isoforms that included both the first extracellular Ig-like domain [FGFR1(I)] and the tyrosine kinase domain [FGFR1(III/K)]. It had less pronounced effects on expression of two other FGF receptors, FGFR2 [FGFR2(I)] and FGFR3 [FGFR3(I)] (Fig. 7), with no induction of kinase-containing isoforms of these receptors (data not shown). IL-6 induced delayed expression of FGFR1 isoforms containing the first extracellular domain [FGFR1(I)], and only transient expression of kinase-containing isoforms of this receptor [FGFR1 (III/K)]. Its most pronounced effect was induction of FGFR3 extracellular domains [(FGFR3(I)]. The most dramatic induction of FGFR1 transcripts that include the 

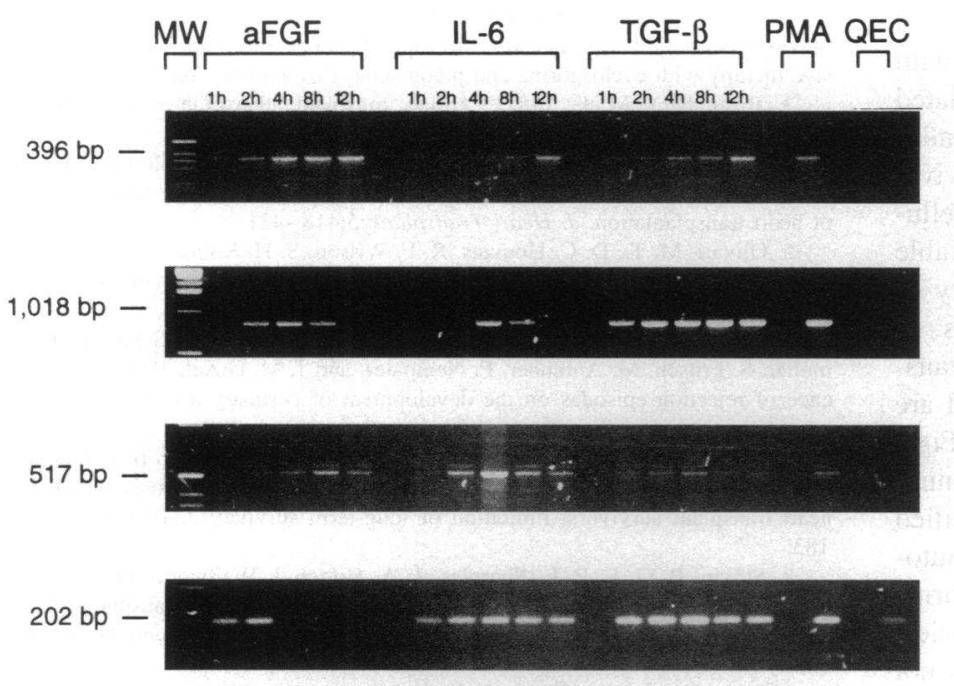

$1,018 \mathrm{bp}-\mathrm{z}$ -
Primer Position

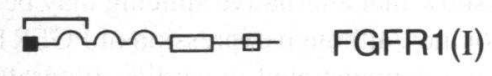

- น

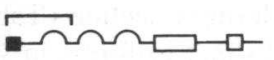

FGFR2(I)

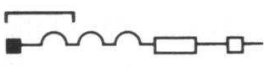

FGFR3(I)

Figure 7. Effects of aFGF and cytokines on FGFR expression in HUVECs. Agarose gel electrophoresis of RT/PCR from HUVECs. Position of the primers is indicated. PCR products amplified for each sample are shown in the same lane. Lane $M W$, DNA molecular weight marker; $a F G F$, HUVECs treated with aFGF $(10 \mathrm{ng} / \mathrm{ml})$ for $1,2,4,8$, or $12 \mathrm{~h} ; I L-6$, HUVECs treated with IL- $6(15 \mathrm{ng} / \mathrm{ml})$ for the time indicated; TGF- $\beta$, HUVECs treated with TGF- $\beta(1 \mathrm{ng} / \mathrm{ml})$ for the time indicated; $P M A$, HUVECs treated with PMA $(100 \mathrm{ng} / \mathrm{ml}, 4 \mathrm{~h}) ; Q E C$, quiescent HUVECs, cultured in growth factor-free medium for $72 \mathrm{~h}$; FGFRI (I), extracellular first Ig-like domain of FGFR1; FGFRI (III/K), transmembrane and tyrosine kinase domains of FGFR1; FGFR2 (I), extracellular Ig-like domain of FGFR2; FGFR3 (I), extracellular Ig-like domain of FGFR3.

kinase domain was seen with TGF- $\beta$ (Fig. 7). Addition of TGF- $\beta$ to quiescent HUVECs resulted in sustained expression of these mRNAs [FGFR1(III/K)] beginning within $1 \mathrm{~h}$ and continuing throughout the $12 \mathrm{~h}$. Interestingly, although it induced similar prolonged expression of the first extracellular domain of FGFR3 [FGFR3(I)], only modest increases in expression of the first Ig-like domain of FGFR1 were found. None of the proteins tested resulted in increased expression of FGFR4 or tyrosine kinase-containing isoforms of FGFR2 or FGFR3 (data not shown).

\section{Discussion}

Accelerated coronary atherosclerosis in transplanted hearts poses serious limits to the long-term success of heart transplantation. In native coronary vessels, advanced atherosclerosis has been described as the end result of an inflammatory, fibroproliferative response to a variety of endothelial injuries (38). Macrophages, $T$ cells, cytokines, and vascular smooth muscle growth factors are clearly part of the response to injury of vascular intima in native atherosclerosis $(16,39,40)$. In cardiac allografts, $T$ cells, which are continually present even in the absence of rejection $(20,37)$, figure prominently in the vasculopathy and are probably the major effectors of immunologic injury. In contrast to the usual exogenous sources of endothelial injury in native atherosclerosis, e.g., hypercholesterolemia, smoking, hypertension, etc., in cardiac allografts, donor class I and class II MHC antigens are themselves the targets of alloreactive $T$ cells. This may in part explain both the high frequency of CAV and the poor correlation of CAV with conventional risk factors for coronary artery disease. The histological differences between atherosclerosis of native coronary arteries and the rap- idly progressive lesions of vessels in transplanted hearts therefore may reflect these differences in the source and mechanisms of endothelial injury or dysfunction.

Our studies show that expression of aFGF is rapidly increased in human hearts after transplantation. The data presented here further suggest that transplantation alters responsiveness to aFGF both through increased expression of FGF receptors and particularly during rejection by modification of alternative splicing that results in the presence of isoforms not found in normal hearts. Both aFGF and its receptors are expressed diffusely and are found in vessels as well as myocytes and infiltrating lymphocytes. These results are compatible with the clinical and pathological features of CAV and its distinction from atherosclerosis of native coronary vessels.

Mechanisms controlling growth factor effects in tissues may be complex and could include both regulation of growth factor expression and regulation of growth factor activity through changes in the number or function of their receptors. Studies reported by Casscells et al. (41) have demonstrated that balloon injury of rat arteries resulted in an increase in FGF receptors in vascular smooth muscle cells, and that SMC proliferation could be inhibited by a basic FGF-saporin conjugate. Banai et al. (18) demonstrated increased intramyocardial vascular proliferative responses to aFGF after ischemic injury. Together with our data, the results suggest that changes in FGF receptor expression may mediate the vascular response to a variety of insults including ischemic and immunologic injury.

Both the structure and function of FGF receptors are complicated due to the presence of multiple genes in the FGFR family and extensive alternative mRNA splicing leading to numerous isoforms of the proteins (22). The experiments reported here show that differential expression of particular alternatively 
spliced transcripts of FGFR1 occurs in cardiac myocytes and vessels of allografts in vivo. The in vitro experiments with endothelial cells show that alternative splicing may be regulated by aFGF and cytokines, although expression of FGFR 1 by endothelial cells was not demonstrated in cardiac allografts in vivo. Expression of FGFR1 isoforms that include only the extracellular Ig-like domains, present at low levels in normal hearts (Table II, Figs. 3-6) (28), is markedly increased in the majority of cardiac allografts. In contrast, transmembrane isoforms of FGFR1 that include the tyrosine kinase domains and may transduce growth signals are not present in normal hearts and are increased in cardiac allografts during rejection (Table II, Figs. 4-6). The functions of these distinct isoforms in vivo cannot be deduced from our data, particularly since mRNAs amplified by the $\mathrm{K}$ primers may include one isoform that does not autophosphorylate (23). Nonetheless, the majority of these isoforms will have normal tyrosine kinase activity. In some biopsies, amplification of exons encoding IIIb or IIIc domains was not accompanied by positive PCR for the kinase domain. This probably reflects different efficiencies of these primer pairs, but could suggest there are other patterns of alternative splicing. The presence of such transmembrane isoforms in two biopsies without rejection on simultaneous histology may reflect the focal nature of rejection.

The novel expression of FGF receptor tyrosine kinase isoforms in association with rejection episodes suggests that events occurring during these episodes may alter normal patterns of alternative mRNA splicing. We have found that expression of IL-6 and TGF- $\beta$ is induced in $60-75 \%$ of allograft biopsies during rejection $(20,37)$, and similar results have been reported recently in animal models of heart transplantation (42). In vitro experiments (Fig. 7) demonstrate that both these factors, but particularly TGF- $\beta$, strongly induce expression of tyrosine kinase-containing FGFR1 transcripts in endothelial cells. These results support the hypothesis that factors produced during rejection may modify normal patterns of mRNA splicing and in doing so alter responsiveness to aFGF.

We hypothesize that the induction of FGF receptor synthesis in the myocardium of transplanted hearts indicates that similar processes may be occurring in the SMC of larger vessels normally affected by CAV. We suspect that the immune processes that induce synthesis of aFGF and its receptors within the myocardium are also occurring within the walls of larger vessels, since endothelial cells and smooth muscle cells can express class II MHC antigens and, therefore, would be targets of the same immune $T$ cells recognizing these antigens within the myocardium. If, as we believe, changes in aFGF production and FGFR expression are important in the genesis of cardiac allograft vasculopathy, prevention of CAV will require interruption of the autocrine and paracrine effects of this growth factor.

\section{Acknowledgments}

The authors would like to thank Dr. Wallace L. McKeehan for providing antibodies to FGF receptor 1, and Drs. Thomas Quertermous, James W. Thomas, and John R. Wilson for their helpful reviews of the manuscript.

This work was supported by National Institutes of Health grant RO1 DK-41312, American Heart Association Tennessee Affiliate New Investigator Award, and the Fleming Foundation.

\section{References}

1. Hosenpud, J. D., G. D. Shipley, and C. R. Wagner. 1992. Cardiac allograft vasculopathy: current concepts, recent developments, and future directions. $J$. Heart Lung Transplant. 11:9-23.
2. Uretsky, B. F., S. Murali, P. S. Reddy, and B. Rabin. 1987. Development of coronary artery disease in cardiac transplant patients receiving immunosuppressive therapy with cyclosporine and prednisone. Circulation. 76:827-834.

3. Billingham, M. E. 1987. Cardiac transplant atherosclerosis. Transplant Proc. 19(Suppl. 5):19-25

4. Narrod, J., R. Kormos, J. Armitage, R. Hardesty, J. Ladowski, and B. Griffith. 1989. Acute rejection and coronary artery disease in long-term survivor of heart transplantation. J. Heart Transplant. 5:418-421.

5. Olivari, M. T., D. C. Homans, R. F. Wilson, S. H. Kubo, and W. S. Ring. 1989. Coronary artery disease in cardiac transplant patients receiving triple-drug immunosuppressive therapy. Circulation. 5(Suppl. III):111-115.

6. Schutz, A., B. M. Kemkes, C. Kugler, C. Angermann, N. Schad, R. Rienmuller, S. Fritsch, M. Anthuber, P. Neumaier, and J. M. Gokel. 1990. The influence of rejection episodes on the development of coronary artery disease after heart transplantation. Eur. J. Cardiothorac. Surg. 4:300-308.

7. Pahl, E., F. J. Fricker, J. Armitage, B. P. Griffith, S. Taylor, B. F. Uretsky, L. B. Beerman, and J. R. Zuberbuhler. 1990. Coronary atherosclerosis in pediatric heart transplant survivors: limitation of long-term survival. J. Pediatr. 2:177183.

8. Stovin, P. G. I., P. L. Sharples, J. A. Hutter, J. Wallwork, and T. A. H. English. 1991. Some prognostic factors for the development of transplant-related coronary artery disease in human cardiac allografts. J. Heart Lung Transplant. $1: 38-44$.

9. Rose, E. A., C. R. Smith, G. A. Petrossian, M. L. Barr, and K. Reemtsma 1989. Humoral immune responses after transplantation: correlation with fatal rejection and graft atherosclerosis. Surgery (St. Louis). 106:203-207.

10. Johnson, D. E., S. Z. Gao, J. Schroeder, W. M. DeCampli, and M. E. Billingham. 1989. The spectrum of coronary artery pathologic findings in human cardiac allografts. J. Heart Lung Transplant. 8:349-359.

11. Ross, R. 1993. Atherosclerosis: current understanding of mechanisms and future strategies in therapy. Transplant Proc. 25:2041-2043.

12. Zerbe, T., B. Uretsky, R. Kormos, J. Armitage, T. Wolyn, B. Griffith, R Hardesty, and R. Duquesnoy. 1992. Graft atherosclerosis: effects of cellular rejection and human lymphocyte antigen. J. Heart Lung Transplant. 11:S104-S110.

13. Barrett, T. B., and E. P. Benditt. 1987. sis (platelet-derived growth factor B chain) gene transcript levels are elevated in human atherosclerosis lesions compared to normal artery. Proc. Natl. Acad. Sci. USA. 84:1099-1103.

14. Barrett, T. B., and E. P. Benditt. 1988. Platelet-derived growth factor gene expression in human atherosclerotic plaques and normal artery wall. Proc. Natl. Acad. Sci. USA. 85:2810-2814.

15. Wilcox, J. N., K. M. Smith, L. T. Williams, S. M. Schwartz, and D. Gordon. 1988. Platelet-derived growth factor mRNA detection in human atherosclerotic plaques by in situ hybridization. J. Clin. Invest. 82:1134-1143.

16. Clinton, S. K., and P. Libby. 1992. Cytokines and growth factors in atherogenesis. Arch. Pathol. Lab. Med. 116:1292-1300.

17. Nabel, E. G., Z.-Y. Yang, G. Plautz, R. Forough, X. Zhan, C. C. Haudenschild, T. Maciag, and G. J. Nabel. 1993. Recombinant fibroblast growth factor-1 promotes intimal hyperplasia and angiogenesis in arteries in vivo. Nature (Lond.). 362:884-887.

18. Banai, S., M. T. Jaklitsch, W. Casscells, M. Shou, S. Shrivastav, R. Correa, S. E. Epstein, and E. F. Unger. 1991. Effects of acidic fibroblast growth factor on normal and ischemic myocardium. Circ. Res. 69:76-85.

19. Isik, F. F., H. A. Valentine, T. O. McDonald, A. Baird, and D. Gordon. 1991. Localization of bFGF in human transplant coronary atherosclerosis. Ann. NY Acad. Sci. 638:487-488.

20. Zhao, X. M., T. K. Yeoh, M. Hiebert, H. Frist, and G. G. Miller. 1993. The Expression of acidic fibroblast growth factor (heparin binding growth factor$1)$ and cytokine genes in human cardiac allografts and T cells. Transplantation (Baltimore). 56:1177-1182.

21. Zhao, X. M., T. K. Yeoh, W. H. Frist, and G. G. Miller. 1994. Induction of fibroblast growth factor and platelet-derived growth factor gene expression in human cardiac allografts. Circulation. In press.

22. Jaye, M., J. Schlessinger, and C. A. Dionne. 1992. Fibroblast growth factor receptor tyrosine kinases: molecular analysis and signal transduction. Biochim. Biophys. Acta. 1135:185-199.

23. Shi, E., M. Kan, J. Xu, F. Wang, J. Hou, and W. L. McKeehan. 1993. Control of fibroblast growth factor receptor kinase signal transduction by heterodimerization of combinatorial splice variants. Mol. Cell. Biol. 13:3907-3918.

24. Johnson, D. E., J. Lu, H. Chen, S. Werner, and L. T. Williams. 1991. The human fibroblast growth factor receptor genes: a common structural arrangement underlies the mechanisms for generating receptor forms that differ in their third immunoglobulin domain. Mol. Cell. Biol. 11:4627-4634.

25. Werner, S., D.-S. R. Duan, C. de Vries, K. G. Peters, D. E. Johnson, and L. T. Williams. 1992. Differential splicing in the extracellular region of fibroblast growth factor receptor 1 generates receptor variants with different ligand-binding specificities. Mol. Cell. Biol. 12:82-88.

26. Gilbert, E., F. D. Gatto, P. Champion-Arnaud, M. C. Gesnel, and R. Breathnach. 1993. Control of BEK and K-SAM splice sites in alternative splicing of the fibroblast growth factor receptor 2 pre-mRNA. Mol. Cell. Biol. 13:54615468 . 
27. Miki, T., D. P. Bottaro, T. P. Fleming, C. L. Smith, W. H. Burgess A. M.-L. Chan, and S. A. Aaronson. 1993. Determination of ligand-binding specificity by alternative splicing: two distinct growth factor receptors encoded by a single gene. Proc. Natl. Acad. Sci. USA. 89:246-250.

28. Luqmani, Y. A., M. Graham, and R. C. Combes. 1992. Expression of basic fibroblast growth factor, FGFR1 and FGFR2 in normal and malignant huma breast, and comparison with other normal tissue. Br. J. Cancer. 66:273-280.

29. Asai, T., A. Wanaka, H. Kato, Y. Masana, M. Seo, and M. Tohyama. 1993. Differential expression of two members of the FGF receptor gene family, FGFR-1 and FGFR-2 mRNA, in the adult rat central nervous system. Mol. Brain Res. 17:174-178.

30. Chomczynski, P., and N. Sacchi. 1987. Single step method of RNA isolation by acid guanidinium thiocyanate-phenol chloroform extraction. Anal. Biochem. 162:156-159.

31. Xu, J., M. Nakahara, J. W. Crabb, E Shi, Y. Matuo, M. Fraser, M. Kan, J. Hou, and W. L. McKeehan. 1992. Expression and immunochemical analysis of rat and human fibroblast growth factor receptor (fig) isoforms. J. Biol. Chem 267:17792-17803.

32. Vainikka, S., J. Partanen, P. Bellosta, P. Coulier, C. Basilico, M. Jaye, and K. Alitalo. 1992. Fibroblast growth factor receptor 4 shows novel features in genomic structure, ligand binding, and signal transduction. EMBO (Eur. Mol Biol. Organ.) J. 11:4273-4280.

33. Kan, M., E. Shi, and W. L. McKeehan. 1991. Identification and assay of fibroblast growth factor receptors. Methods Enzymol. 198:158-171.

34. Houssaint, E., P. R. Blanquet, P. Champion-Arnaud, M. C. Gesnel, A Torriglia, Y. Courtois, and R. Breathnach. 1990. Related fibroblast growth factor receptor genes exist in the human genome. Proc. Natl. Acad. Sci. USA. 87:81808184.

35. Dionne, C. A., G. Crumley, F. Bellot, J. M. Kaplow, G. Searfoss, M. Ruta, W. H. Burgess, M. Jaye, and J. Schlessinger. 1990. Cloning and expression of two distinct high-affinity receptors cross-reacting with acidic and basic fibroblast growth factors. EMBO (Eur. Mol. Biol. Organ.) J. 9:2685-2692.

36. Keegan, K., D. E. Johnson, L. T. Williams, and M. J. Hayman. 1991. Isolation of an additional member of the fibroblast growth factor receptor family, FGFR3. Proc. Natl. Acad. Sci. USA. 88:1095-1099.

37. Zhao, X. M., W. H. Frist, T. K. Yeoh, and G. G. Miller. 1993. Expression of cytokine genes in human cardiac allografts: correlation of IL-6 and TGF-beta with histological rejection. Clin. Exp. Immunol. 93:448-451.

38. Ross, R. 1993. The pathogenesis of atherosclerosis: a perspective for the 1990's. Nature (Lond.). 362:801-809.

39. Libby, P., S. J. C. Warner, and R. N. Solomon. 1988. Production of platelet-derived growth factor-like mitogen by smooth-muscle cells from human atheroma. N. Engl. J. Med. 318:1493-1498.

40. Libby, P., D. Schwartz, E. Brogi, H. Tanaka, and S. K. Clinton. 1992 A cascade model for restenosis, a specific case of atherosclerosis progression. Circulation. 86(Suppl. 3):11147-11152.

41. Casscells, W., D. A. Lappi, B. B. Olwin, C. Wai, M. Siegman, E. H. Speir, J. Sasse, and A. Baird. 1992. Elimination of smooth muscle cells in experimenta restenosis: targeting of fibroblast growth factor receptors. Proc. Natl. Acad. Sci. USA. 89:7159-7163.

42. Waltenberger, J., A. Wanders, B. Fellstrom, and K. Miyazono. 1993. Induction of transforming growth factor-beta during cardiac allograft rejection. J. Immunol. 151:1147-1157. 